\title{
Segmental ureterectomy can be performed safely in patients with urothelial carcinoma of distal ureter
}

Zhuo Jia ; Yanqing Gong*; Cuijian Zhang; Zhengqing Bao; Xuesong Li; Han Hao; Gengyan Xiong; Lei Zhang; Dong Fang; Zhisong He; Liqun Zhou

*Co-first authors

Department of Urology, Peking University First Hospital, Institute of Urology and National Urological Cancer Center, Peking University, Peking University, Beijing, China

Funding: The work was supported by the Clinical Features Research of Capital (No.

Z151100004015173) and the Capital Health Research and Development of Special (No. 2016-1-4077).

Cite as: Can Urol Assoc J 2018 November 20; Epub ahead of print. http://dx.doi.org/10.5489/cuaj.5555

Published online November 20, 2018

$* * *$

\section{Abstract}

Introduction: We aimed to compare oncological outcomes by surgery type (segmental ureterectomy [SU] vs. radical nephroureterectomy [RNU]) in a large cohort of patients with upper tract urothelial carcinoma (UTUC) of the distal ureter. Methods: We performed a retrospective analysis of 219 patients with UTUC of the distal ureter among 931 patients with UTUC who underwent SU and RNU.

Clinicopathological outcomes were evaluated. Cancer-specific survival (CSS), overall survival (OS), local recurrence-free survival (RFS), intravesical recurrence-free survival (IVRFS), contralateral recurrence-free survival, and distal metastasis-free survival were assessed by the Kaplan-Meier method and Cox regression, estimating hazard ratios (HR) and 95\% confidence intervals (CIs).

Results: A total of 179 (81.7\%) patients underwent RNU and 40 (18.3\%) underwent SU: 85 males (47.5\%) with RNU and 17 (42.5\%) with SU ( $\mathrm{p}=0.568)$. The median age with RNU and SU was 71 years (range 31-86) and 70 years (range 46-90), respectively ( $p=0.499)$. The $\mathrm{T}$ stage of the two groups did not differ $(\mathrm{p}=0.122)$, nor did mean tumour length ( $3.35 \pm 2.62$ vs. $3.25 \pm 2.14$; $\mathrm{p}=0.953)$, grade $(\mathrm{p}=0.075)$, tumour 
necrosis ( $\mathrm{p}=0.634$ ), or followup time (months) (58.1 \pm 8.1 vs. $63.7 \pm 3.4 ; \mathrm{p}=0.462$ ). The two groups did not differ in CSS ( $\mathrm{p}=0.358$ ) or OS ( $\mathrm{p}=0.206)$, and surgery type did not predict CSS (HR 0.862; 95\% CI 0.469-1.585; p=0.633) or OS (HR 0.764; 95\% CI 0.419-1.392; $\mathrm{p}=0.379$ ). Local RFS was higher with RNU than SU (96.2\% vs. 86.0\%; $\mathrm{p}=0.02$ ), but the groups did not differ in IVRFS ( $\mathrm{p}=0.661)$, contralateral RFS ( $\mathrm{p}=0.183$ ), or distant metastasis-free survival $(\mathrm{p}=0.078)$. On multivariate analysis, $\mathrm{SU}$ was associated with local RFS (HR 5.069; 95\% CI 1.029-24.968; $\mathrm{p}=0.046$ ) and distant metastasis-free survival (HR 6.497; 95\% CI 1.196-35.283; $\mathrm{p}=0.03$ ). Local RFS was lower with SU than RNU for patients with pT3-4 stage ( $\mathrm{p}=0.006)$.

Conclusions: Long-term oncological outcomes were equivalent with SU and RNU in patients with UTUC of the distal ureter. SU affected local recurrence survival, especially with advanced tumour stage, and distant metastasis survival.

\section{Introduction}

Upper tract urothelial carcinoma (UTUC) is an uncommon disease and accounts for 7\% to $8 \%$ of all renal tumors and $5 \%$ to $10 \%$ of all urothelial carcinomas [1-2]. The standard option for UTUC treatment remains radical nephroureterectomy (RNU) because of the aggressiveness of the disease. However, segmental ureterectomy (SU) is increasingly being chosen for better preservation of postoperative renal function, especially for patients with chronic renal insufficiency, solitary kidney or bilateral synchronous disease[3-5]. To our knowledge, cancer-specific survival (CSS) and recurrence-free survival after SU is not clear, and the indication of SU is debatable.

Here we compared oncologic outcomes by surgery type (SU vs RNU) in a large cohort of patients with UTUC of the distal ureter, which could be meaningful for management of UTUC.

\section{Methods}

\section{Patients}

A series of 931 UTUC patients who had undergone surgery at our institution from January 2000 to April 2014 was retrospectively analyzed. We included 248 patients with tumors localized at the distal ureter (defined as below the level of iliac vessels) and who underwent SU or RNU. We excluded patients with evidence of metastatic disease at the time of diagnosis, other malignancies or incomplete follow-up data. Patients were preoperatively evaluated by imaging (ultrasonography, CT, MRI or 
intravenous urography) and urine cytology and cystoscopy. Preoperative ureteroscopy with biopsy was not routinely assessed in case of inconclusive diagnosis.

For patients who were followed at our institute, the follow-up regimen included cystoscopy every 3 months for the first 2 years. The follow-up intervals were extended to half a year up to 5 years after surgery and 1 year thereafter. Chest $\mathrm{X}$-ray, urine cytology, serum creatine measurement, and abdominal ultrasonography or CT/MRI were performed at the same time.

\section{Statistical analysis}

Patients were divided into 2 groups by surgery type, SU or RNU. The following clinical and pathologic variables were reviewed: sex, age, BMI, previous history of UTUC and bladder carcinoma, surgical procedure, tumor length and side, tumor stage and grade, lymphovascular invasion (LVI) and necrosis. Clinical and pathologic characteristics were compared by Wilcoxon test, chi-square test or Fisher exact test. CSS, overall survival (OS), local recurrence-free survival, intravesical recurrence-free survival (IVRFS), contralateral recurrence-free survival and distant metastasis-free survival were analyzed by the Kaplan-Meier method with the log-rank test. Univariable analysis with the log-rank test and multivariable analysis with the Cox proportional-hazards regression model were used, estimating hazard ratios (HRs) and 95\% confidence intervals (CIs). Two-tailed $\mathrm{p}<0.05$ was considered statistically significant.

\section{Results}

\section{Clinicopathological characteristics}

The clinical and pathological characteristics of the 219 patients included are in Table 1 and Table 2; 179 (81.7\%) underwent RNU and 40 (18.3\%) underwent SU. The RNU group had 85 males (47.5\%) and the SU group 17 males $(42.5 \%)(\mathrm{p}=0.568)$. The median age was 71 years (range 31-86) and 70 years (range 46-90), respectively $(p=0.499)$. Also, the mean BMI was similar $(p=0.485)$. The two groups did not differ in history of UTUC and bladder carcinoma (6.1\% vs 7.5\%, p=0.724; $14.0 \%$ vs $12.5 \%$, $\mathrm{p}=0.806)$. Surgery was performed by laparoscopy for $71 \mathrm{RNU}$ patients (39.7\%) and 12 SU patients (30.0\%) ( $\mathrm{p}=0.255)$. And surgery was performed in retroperitoneal approach in $145 \mathrm{RNU}$ patients (81.0\%) and $34 \mathrm{SU}$ patients (85.0\%) ( $\mathrm{p}=0.554)$. There were 2 patients (5.0\%) had undergone lymph node dissection in SU group and 24 patients (13.4\%) in RNU group ( $\mathrm{p}=0.137)$. The $\mathrm{T}$ stage of the two groups did not differ ( $\mathrm{p}=0.122$ ), and no lymph node metastasis was found in all patients. The groups 
did not differ in mean tumor length (3.35 \pm 2.62 vs $3.25 \pm 2.14, \mathrm{p}=0.953)$, tumor grade $(\mathrm{p}=0.075)$ or rate of necrosis $(\mathrm{p}=0.634)$.

\section{CSS and OS}

The mean follow-up time (months) did not differ between RNU and SU groups (58.1 \pm 8.1 vs $63.7 \pm 3.4, p=0.462$ ), and CSS and OS did not differ ( $\mathrm{p}=0.358$ and $\mathrm{p}=0.206$ ) (Fig. 1).

On multivariable analysis, age, history of UTUC and tumor length were significantly associated with both CSS and OS (Table 3). However, the surgery type, RNU or SU, did not predict CSS (HR=0.862, 95\% CI 0.469-1.585, $\mathrm{p}=0.633$ ) or OS (HR=0.764, 95\% CI 0.419-1.392, $\mathrm{p}=0.379)$.

\section{Recurrence and distant metastasis}

The 5-year local recurrence-free survival was $96.2 \%$ and $86.0 \%$ with RNU and SU ( $\mathrm{p}=0.02$ ) (Fig. 2a). On multivariable analysis, local recurrence-free survival was associated with SU (HR=5.069, 95\% CI 1.029-24.968, p=0.046) (Table 4). The 5-year IVRFS was $45.4 \%$ and $46.4 \%$ with RNU and SU ( $p=0.661$ ) (Fig. 2b). On multivariable analysis, IVRFS was associated with history of bladder carcinoma $(\mathrm{HR}=2.129,95 \% \mathrm{CI}$ 1.385-3.273, $\mathrm{p}=0.001)$ and tumor necrosis $(\mathrm{HR}=2.12,95 \% \mathrm{CI}$ 1.212-3.708, $\mathrm{p}=0.008)$. The 5-year contralateral recurrence-free survival with RNU and SU was $89.6 \%$ and $92.9 \%(p=0.183)$ (Fig. 2c). On multivariable analysis, contralateral recurrence-free survival was associated with age and BMI of patients and tumor length. The 5-year distant metastasis-free survival with RNU and SU was 96.0\% and 90.3\% ( $\mathrm{p}=0.078$ ) (Fig. 2d). On multivariable analysis, distant metastasis-free survival was associated with SU (HR=6.497, 95\% CI 1.196-35.283, $\mathrm{p}=0.03)$.

On stratification by T stage (pTa-T2 vs pT3-T4), CSS, OS, contralateral recurrence-free survival, IVRFS and distant metastasis-free survival did not differ by RNU or SU (data not shown). For patients with pTa-T2, local recurrence-free survival did not differ by surgery type ( $p=0.296$ ) (Fig. 3). However, for patients with pT3-T4, local recurrence-free survival was shorter with SU than RNU ( $p=0.006)$ (Fig. 3). The site of local recurrence after SU in the three patients was ureteral residue. Two of the three patients took further surgery and the other one patient took chemotherapy for treatment. 


\section{Discussion}

We aimed to compare oncologic outcomes by surgery type (SU vs RNU) in a large cohort of patients with UTUC of the distal ureter. Long-term oncologic outcomes were equivalent with SU and RNU in patients with UTUC of the distal ureter. SU affected local recurrence survival and distant metastasis survival. Local recurrence-free survival was lower with SU than RNU for patients with advanced disease stage.

In the 2017 European Association of Urology Guidelines, RNU is the standard for high-risk UTUC, regardless of tumor location[6]. In low-risk cancers, which are unifocal, small, low-grade and with no infiltration seen on CT or urography, survival with kidney-sparing surgery (i.e., ureteroscopy or SU) is similar to that with RNU [7]. In high-risk cancers, kidney-sparing surgery can also be considered with renal insufficiency or solitary functional kidney $[3,8]$. As compared with SU, ureteroscopy has several drawbacks such as lack of pathological specimens if treated by laser generator and lymphadenectomy is not possible, which is important in evaluating the stage and grade[8,9]. Thus, SU is favoured instead of RNU in some situations. However, cancer-specific and recurrence-free survival was unknown with SU.

A retrospective study of more than 2000 patients with UTUC showed no significant difference in cancer-specific survival with SU and RNU [8]. Another study revealed that SU or RNU was not a predictor of CSS on multivariable analysis and CSS or recurrence-free survival did not differ on Kaplan-Meier analyses[10]. Few studies of survival and recurrence for tumors at the distal ureter have been reported. Whether SU could be used in high-risk tumors is still controversial. Bin et al.[11] showed no significant difference in CSS with proximal, middle, or distal tumor location of ureter UTUC.

In our study, the clinicopathologic characteristics of patients with SU and RNU, including TNM stage and tumor grade, did not differ, so the results of CSS, OS and recurrence-free survival were less influenced. The surgery type, SU and RNU, did not affect CSS or OS. Several studies also found CSS and OS comparable with SU and RNU in patients with UTUC of the distal ureter[7,12,13]. Furthermore, we found older age, advanced T stage, and length of tumor associated with CSS and OS with UTUC, which agreed with results from the literature.

The two groups did not differ in rate of local recurrence, bladder recurrence, contralateral recurrence and distant metastasis. The rate of bladder recurrence after RNU for UTUC is $22 \%$ to $47 \%[7,14]$. However, we found a bladder recurrence rate of $57.0 \%$ with RNU and $55.0 \%$ with SU. Lower ureter lesion was previously found an 
independent predictor of bladder recurrence in patients with UTUC treated with RNU[15], which may explain why we found a higher rate of bladder recurrence. A systematic review and meta-analysis of bladder recurrence after RNU found ureteral location, necrosis, a laparoscopic approach, intravesical bladder-cuff removal and positive surgical margins linked to bladder recurrence. Ureteral tumor location was a significant predictor of bladder recurrence (HR=1.27, 95\% CI 1.14-1.42, $\mathrm{p}<0.001)$ [7]. Fradet et al[14] showed tumors located at both the renal pelvis and ureter, older age and laparoscopic surgery as risk factors of bladder recurrence after RNU. Our study found that surgery type, SU or RNU, was not associated with IVRFS, but IVRFS could be predicted by history of bladder carcinoma and tumor necrosis, which agreed with the literature. Furthermore, Liu et al.[16], in a retrospective analysis of 664 UTUC patients who underwent RNU, found diagnostic ureteroscopy as an independent risk factor of IVRFS. The Sung et al. study had a similar conclusion [17].

Few studies have investigated local recurrence-free, contralateral-free and distant metastasis-free survival. Hung et al. showed no significant differences in local recurrence-free survival $(\mathrm{p}=0.302)$ and distant metastasis-free survival $(\mathrm{p}=0.219)$ with SU and RNU [18]. In our study, local recurrence-free survival was lower with SU than RNU, and SU was associated with reduced distant metastasis-free survival. The two groups did not differ in contralateral recurrence-free survival. The tumors investigated in the Hung et al. study were in the whole ureter, whereas our tumors were at the distal ureter, which may explain the differences in results.

Local recurrence-free survival was lower with SU than RNU for patients with pT3-4 stage, but with no effect on CSS, OS, IVRFS, contralateral-free survival or distant metastasis-free survival versus RNU. The Jeldres et al. study showed no difference in CSS with RNU versus SU in patients with pT1-2N0M0 and pT3-4N0M0 [8]. Other researchers implied that patients with locally advanced stage disease should not be excluded from consideration for SU $[8,13]$.

The most important advantage of SU might be its better protection of postoperative renal function. SU could contribute to good preservation of renal function[19]. We have few studies about the relation between renal function and prognostic outcomes of patients with UTUC. One study showed decreased glomerular filtration rate after RNU, and renal function was not associated with disease recurrence, CSS or OS. Furthermore, the results were similar when restricted to patients with locally advanced disease (pT3-pT4) [20].

A systematic review and meta-analysis showed that cisplatin-based adjuvant systemic chemotherapy was beneficial for OS and disease-free survival with UTUC; 
non-cisplatin-based chemotherapy had no benefit[21]. However, not all patients could receive cisplatin-based adjuvant chemotherapy because of impaired renal function. Thus, more patients could receive chemotherapy for better preservation of renal function with SU. However, we have insufficient data and still need further prospective studies. Furthermore, Xylinas et al. found that in patients without adjuvant chemotherapy and disease recurrence, better renal function was associated with better OS [20].

This study was the most comprehensive of the prognostic outcomes of patients with UTUC in the distal ureter with SU and RNU because we investigated CSS, OS, local recurrence-free survival, IVRFS, contralateral recurrence-free survival, and distal metastasis-free survival and in different tumor stages. The major limitation of our study was its single-center retrospective design. A multicenter randomized controlled trial is needed to investigate the prognostic difference of SU and RNU and the proper indications of SU.

\section{Conclusions}

Our study suggests that SU and RNU have equivalent long-term prognostic outcomes for patients with UTUC of the distal ureter. However, SU can affect local recurrence survival and distant metastasis survival. With advanced $\mathrm{T}$ stage, local recurrence-free survival is lower with SU than RNU. Thus, SU could be used for low-risk tumors similar to RNU and should not be excluded in patients with advanced disease. Patients who underwent SU need to be followed up carefully. 


\section{References}

1. Siegel RL, et al. Cancer statistics, 2015. CA Cancer J Clin, 2015.65:5.

2. Munoz JJ, Ellison LM. Upper tract urothelial neoplasms: incidence and survival during the last 2 decades. J Urol 2000;164:1523-5.

3. Colin P, Ouzzane A, Pignot G, et al. Comparison of oncological outcomes after segmental ureterectomy or radical nephroureterectomy in urothelial carcinomas of the upper urinary tract: results from a large French multicentre study. BJU Int. 2012;110:1134-1141.

4. Pohar KS, Sheinfeld J. When is partial ureterectomy acceptable for transitional-cell carcinoma of the ureter? J Endourol. 2001;15: 405-408.

5. Oosterlinck W, Solsona E, van der Meijden AP, et al. EAU guidelines on diagnosis and treatment of upper urinary tract transitional cell carcinoma. Eur Urol. 2004;46:147-154.

6. Margulis V, et al. Outcomes of radical nephroureterectomy: a series from the Upper Tract Urothelial Carcinoma Collaboration. Cancer, 2009. 115: 1224.

7. Seisen, T., et al. Oncologic Outcomes of Kidney-sparing Surgery Versus Radical Nephroureterectomy for Upper Tract Urothelial Carcinoma: A Systematic Review by the EAU Nonmuscle Invasive Bladder Cancer Guidelines Panel. Eur Urol, 2016. 70: 1052.

8. Jeldres C, Lughezzani G, Sun M, et al. Segmental ureterectomy can safely be performed in patients with transitional cell carcinoma of the ureter. J Urol. 2010;183:1324-1329.

9. Roupret M, Harmon JD, Sanderson KM et al. Laparoscopic distal ureterectomy and anastomosis for management of low-risk upper urinary tract transitional cell carcinoma: preliminary results. BJU Int 2007; 99: 623-7.

10. Bagrodia A, Kuehhas FE, Gayed BA et al. Comparative Analysis of Oncologic Outcomes of Partial Ureterectomy vs Radical Nephroureterectomy in Upper Tract Urothelial Carcinoma. UROLOGY 81 (5), 2013.

11. Bin X, Roy OP, Ghiraldi E et al (2012) Impact of tumour location and surgical approach on recurrence-free and cancer-specific survival analysis in patients with ureteric tumours. BJU Int (Epub ahead of print.

12. Hiroshi Fukushima, Kazutaka Saito, Junichiro Ishioka, et al. Euivalent survival and improved preservation of renal function fter distal ureterectomy compared with nephroureterectomy in atients with urothelial carcinoma of the 
distal ureter: A propensity score-matched multicenter study. International Journal of Urology (2014) 21, 1098-1104.

13. Dalpiaz O, Ehrlich G, Quehenberger F et al. Distal ureterectomy is a safe surgical option in patients with urothelial carcinoma of the distal ureter. Urologic Oncology: Seminars and Original Investigations 32 (2014) 34.e134.e8.

14. Fradet V et al. Risk factors for bladder cancer recurrence after nephroureterectomy for upper tract urothelial tumors: results from the Canadian Upper Tract Collaboration. Urol Oncol, 2014. 32: 839.

15. Otsuka M, Taguchi S, Nakagawa T et al. Lower ureteral lesion is an independent predictor of intravesical recurrence after radical nephroureterectomy for upper tract urothelial carcinoma. Urol Oncol. 2016 Feb;34(2):59.e9-13.

16. Liu P, Su XH, Xiong GY, et al. Diagnostic Ureteroscopy for Upper Tract Urothelial Carcinoma is Independently Associated with Intravesical Recurrence after Radical Nephroureterectomy.Int Braz J Urol. 2016 Nov-Dec;42(6):1129-1135.

17. Sung HH, Jeon HG, Han DH et al. Diagnostic Ureterorenoscopy Is Associated with Increased Intravesical Recurrence following Radical Nephroureterectomy in Upper Tract Urothelial Carcinoma.PLoS One. 2015 Nov 10;10(11):e0139976.

18. Hung SY, Yang WC, Luo HL et al. Segmental ureterectomy does not compromise the oncologic outcome compared with nephroureterectomy for pure ureter cancer.Int Urol Nephrol. 2014 May;46(5):921-6.

19. Silberstein JL, Power NE, Savage C et al. Renal function and oncologic utcomes of parenchymal sparing ureteral resection versus radical ephroureterectomy for upper tract urothelial carcinoma. Urol. 2012; 187: 2934.

20. Xylinas E, Rink M, Margulis V, et al. Impact of renal function on eligibility for chemotherapy and survival in patients who have undergone radical nephro-ureterectomy. BJU Int. 2013 Aug;112(4):453-61.

21. Leow JJ, Martin-Doyle W, Fay AP, et al. A systematic review and meta-analysis of adjuvant and neoadjuvant chemotherapy for upper tract urothelial carcinoma. Eur Urol. 2014 Sep;66(3):529-41. 


\section{Figures and Tables}

Fig. 1. Survival curves in patients by surgery type. The dots represent censored observations.

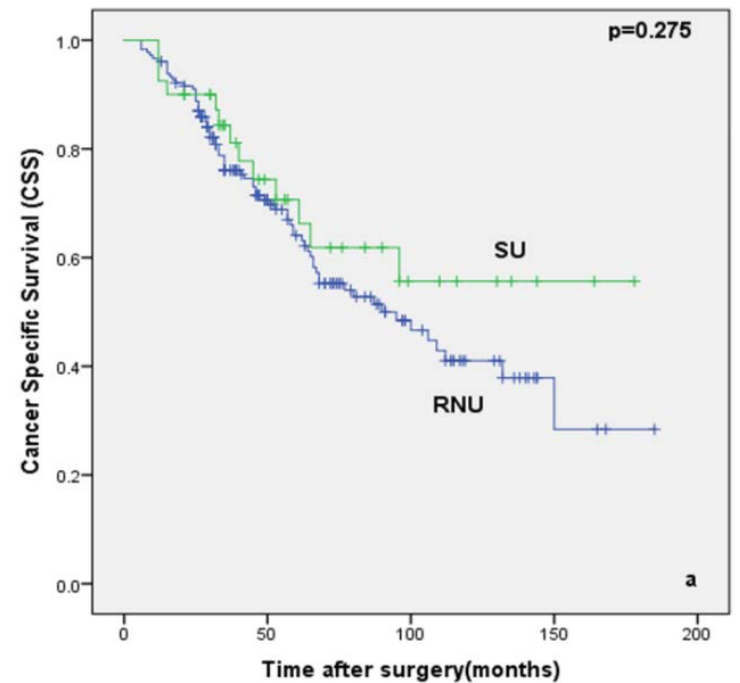

\begin{tabular}{|l|c|c|c|c|c|c|c|}
\hline $\begin{array}{l}\text { Number } \\
\text { at risk }\end{array}$ & 0 & 20 & 40 & 60 & 80 & 100 & 120 \\
\hline RNU & 179 & 163 & 100 & 66 & 42 & 26 & 15 \\
\hline SU & 40 & 36 & 23 & 16 & 11 & 7 & 5 \\
\hline
\end{tabular}

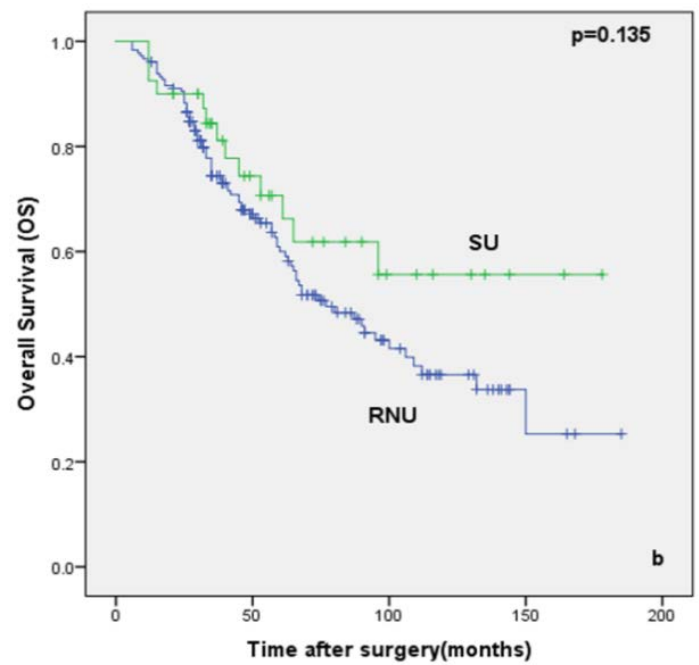

\begin{tabular}{|l|c|c|c|c|c|c|c|}
\hline $\begin{array}{l}\text { Number } \\
\text { at risk }\end{array}$ & 0 & 20 & 40 & 60 & 80 & 100 & 120 \\
\hline RNU & 179 & 163 & 100 & 66 & 42 & 26 & 15 \\
\hline SU & 40 & 36 & 23 & 16 & 12 & 7 & 5 \\
\hline
\end{tabular}


Fig. 2. Survival curves in patients by surgery type. (A) Local recurrence-free survival; (B) IVRFS; (C) contralateral recurrence-free survival; and (D) distant metastasis-free survival. The dots represent censored observations.

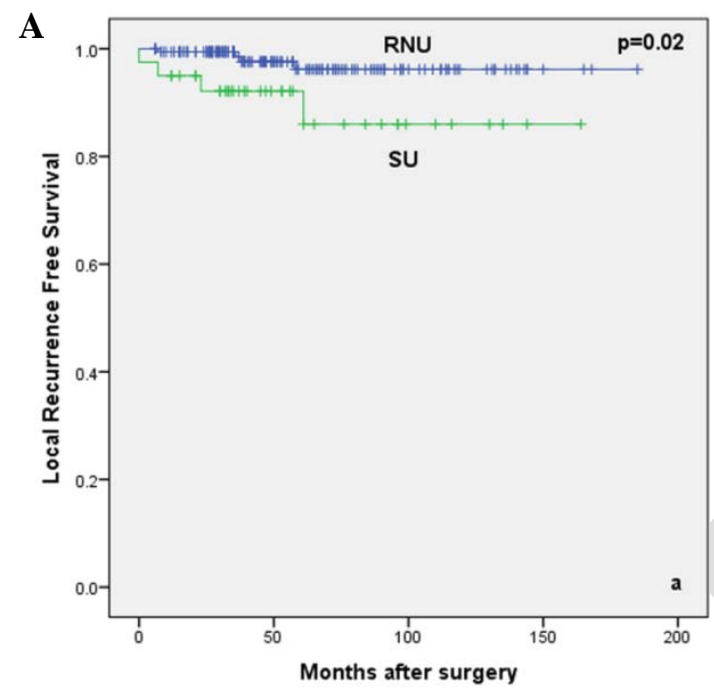

\begin{tabular}{|l|c|c|c|c|c|c|c|}
\hline $\begin{array}{l}\text { Number } \\
\text { at risk }\end{array}$ & 0 & 20 & 40 & 60 & 80 & 100 & 120 \\
\hline RNU & 179 & 162 & 98 & 65 & 42 & 26 & 15 \\
\hline SU & 40 & 35 & 22 & 15 & 11 & 6 & 4 \\
\hline
\end{tabular}

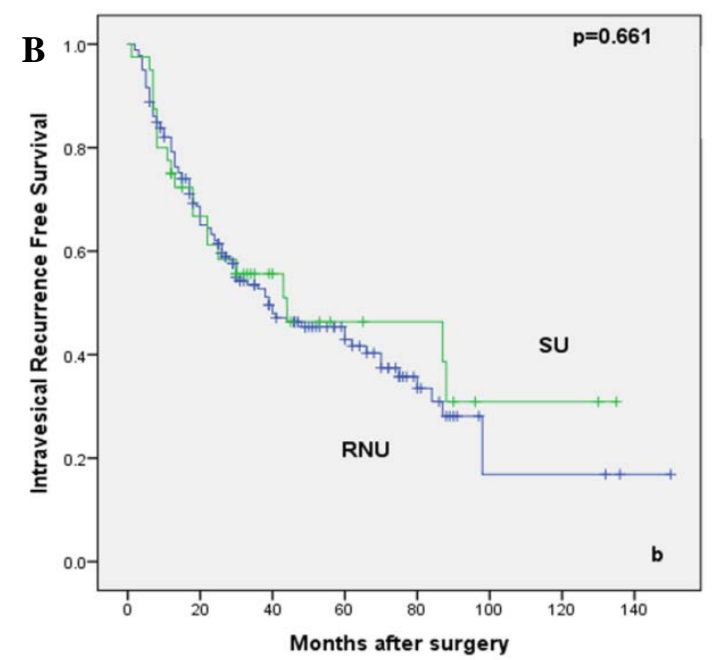

\begin{tabular}{|l|c|c|c|c|c|c|c|}
\hline $\begin{array}{l}\text { Number } \\
\text { at risk }\end{array}$ & 0 & 20 & 40 & 60 & 80 & 100 & 120 \\
\hline RNU & 179 & 113 & 60 & 36 & 14 & 3 & 3 \\
\hline SU & 40 & 24 & 12 & 7 & 6 & 2 & 2 \\
\hline
\end{tabular}




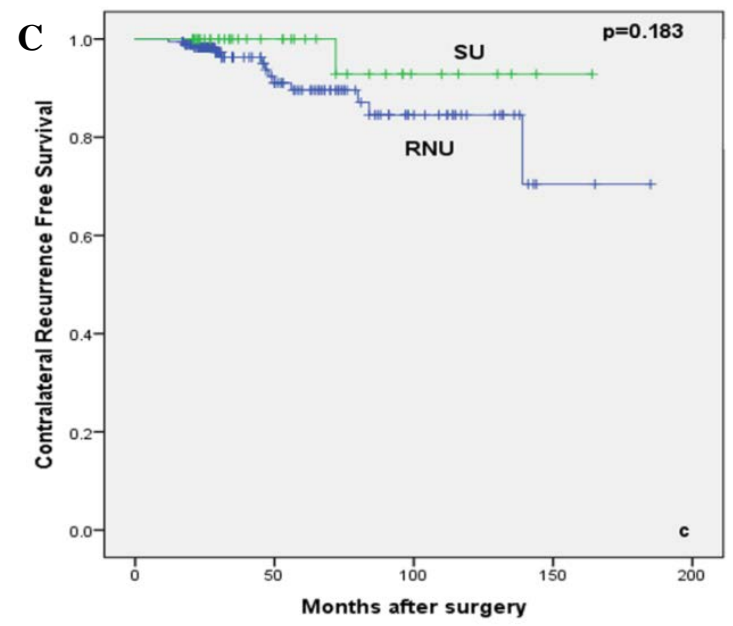

\begin{tabular}{|l|c|c|c|c|c|c|c|}
\hline $\begin{array}{l}\text { Number } \\
\text { at risk }\end{array}$ & 0 & 20 & 40 & 60 & 80 & 100 & 120 \\
\hline RNU & 179 & 165 & 80 & 56 & 35 & 21 & 12 \\
\hline SU & 40 & 39 & 21 & 16 & 11 & 6 & 4 \\
\hline
\end{tabular}

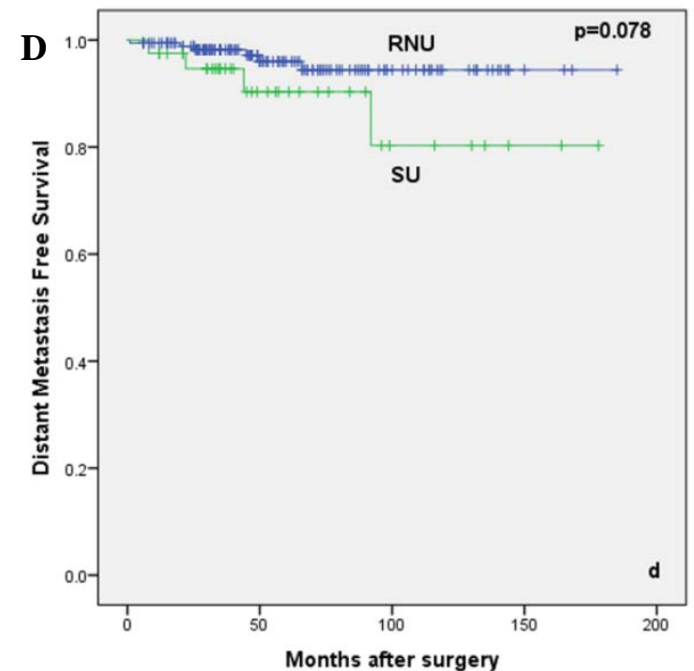

\begin{tabular}{|l|c|c|c|c|c|c|c|}
\hline $\begin{array}{l}\text { Number } \\
\text { at risk }\end{array}$ & 0 & 20 & 40 & 60 & 80 & 100 & 120 \\
\hline RNU & 179 & 161 & 99 & 65 & 42 & 26 & 15 \\
\hline SU & 40 & 36 & 22 & 15 & 11 & 6 & 5 \\
\hline
\end{tabular}


Fig. 3. Local recurrence-free survival curves by surgery type. The dots represent censored observations.

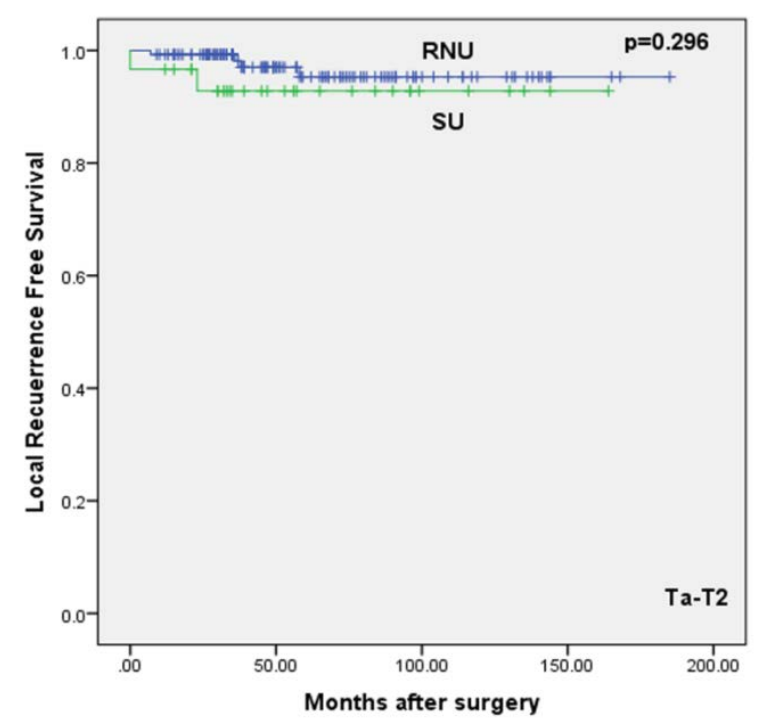

\begin{tabular}{|l|c|c|c|c|c|c|c|}
\hline $\begin{array}{l}\text { Number } \\
\text { at risk }\end{array}$ & 0 & 20 & 40 & 60 & 80 & 100 & 120 \\
\hline RNU & 139 & 127 & 79 & 54 & 35 & 19 & 13 \\
\hline SU & 30 & 27 & 17 & 12 & 10 & 5 & 4 \\
\hline
\end{tabular}

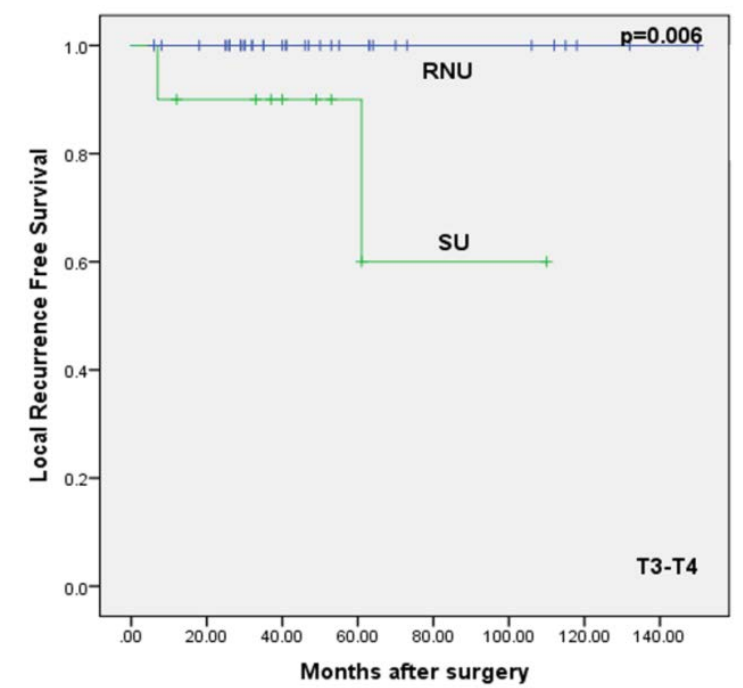

\begin{tabular}{|l|c|c|c|c|c|c|c|}
\hline $\begin{array}{l}\text { Number } \\
\text { at risk }\end{array}$ & 0 & 20 & 40 & 60 & 80 & 100 & 120 \\
\hline RNU & 40 & 35 & 19 & 12 & 7 & 7 & 2 \\
\hline SU & 10 & 8 & 5 & 3 & 2 & 2 & 0 \\
\hline
\end{tabular}




\begin{tabular}{|l|c|c|c|c|}
\hline \multicolumn{5}{|l|}{$\begin{array}{l}\text { Table 1. Association between surgery type (radical nephroureterectomy [RNU] } \\
\text { and segmental ureterectomy [SU]) and preoperative clinical characteristics of } \\
\text { patients with upper tract urothelial carcinoma (UTUC) of the distal ureter }\end{array}$} \\
\hline & $\begin{array}{c}\text { RNU } \\
\text { n=179 }\end{array}$ & $\begin{array}{c}\text { SU } \\
\text { n=40 }\end{array}$ & $\begin{array}{c}\text { Chi-square } \\
\text { or Z Z }\end{array}$ & p \\
\hline Male (\%) & $85(47.5 \%)$ & $17(42.5 \%)$ & 0.327 & 0.568 \\
\hline Median age (range) & $71(31-86)$ & $70(46-90)$ & -0.677 & 0.499 \\
\hline BMI, mean \pm SD & $24.38 \pm 3.43$ & $24.98 \pm 3.83$ & -0.698 & 0.485 \\
\hline History of UTUC & $11(6.1 \%)$ & $3(7.5 \%)$ & & 0.724 \\
\hline $\begin{array}{l}\text { History of bladder } \\
\text { carcinoma }\end{array}$ & $25(14.0 \%)$ & $5(12.5 \%)$ & 0.432 & 0.806 \\
\hline $\begin{array}{l}\text { Surgical procedure, } \\
\text { laparoscopy }\end{array}$ & $71(39.7 \%)$ & $12(30.0 \%)$ & 1.298 & 0.255 \\
\hline $\begin{array}{l}\text { Surgical approach, } \\
\text { retroperitoneal }\end{array}$ & $145(81.0 \%)$ & $34(85.0 \%)$ & 0.349 & 0.554 \\
\hline Tumor side, left & $88(49.2 \%)$ & $16(40.0 \%)$ & 2.737 & 0.254 \\
\hline $\begin{array}{l}\text { Lymph node } \\
\text { dissection }\end{array}$ & $24(13.5 \%)$ & $2(5.0 \%)$ & 2.209 & 0.137 \\
\hline
\end{tabular}

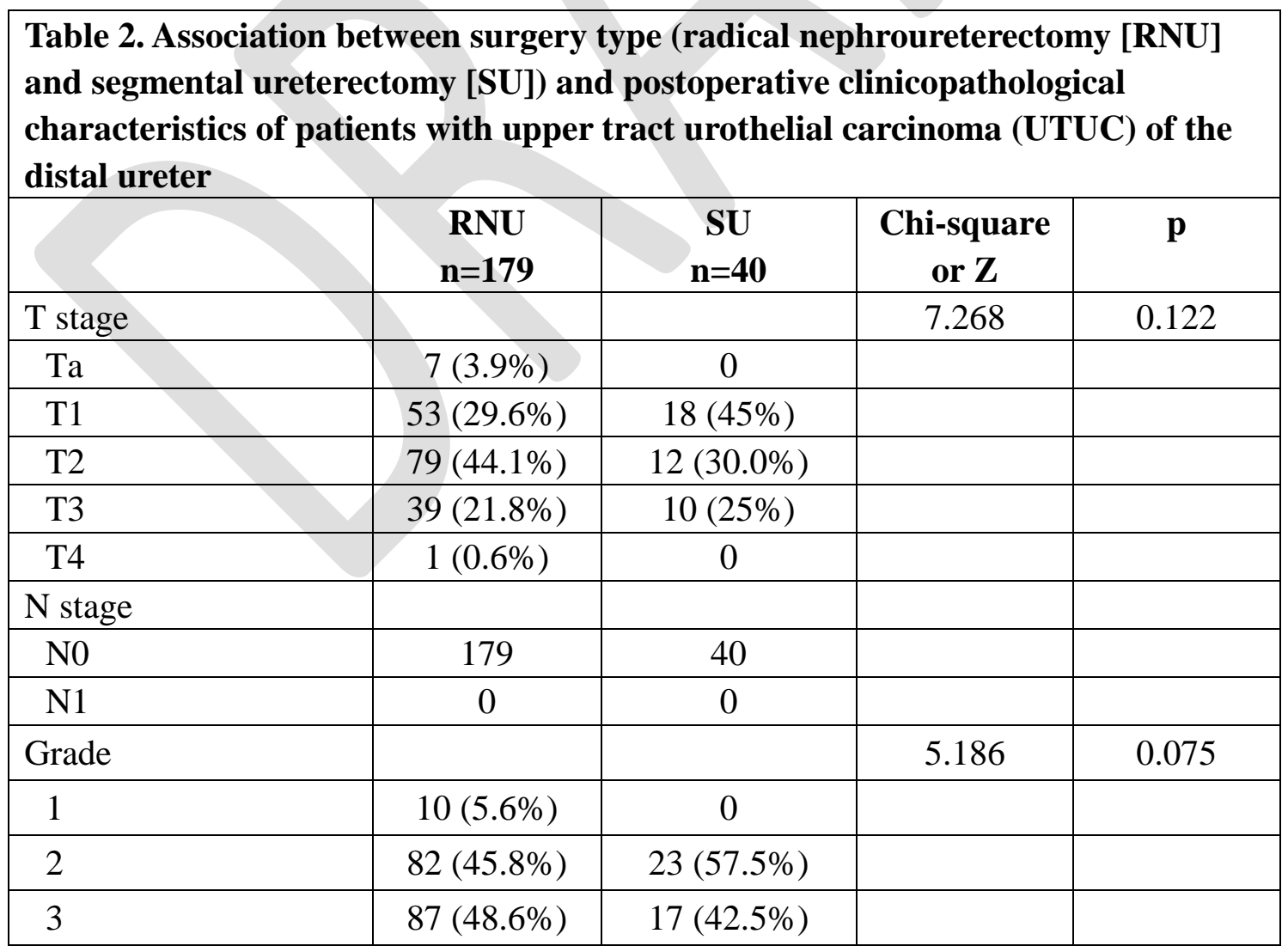




\begin{tabular}{|l|c|c|c|c|}
\hline LVI & $10(5.6 \%)$ & $2(5.0 \%)$ & & 1 \\
\hline Tumour length & $3.35 \pm 2.62$ & $3.25 \pm 2.14$ & 0.059 & 0.953 \\
\hline Necrosis & $26(14.5 \%)$ & $7(17.5 \%)$ & 0.226 & 0.634 \\
\hline eGFR difference & $25.09 \pm 18.45$ & $20.14 \pm 16.29$ & -0.249 & 0.840 \\
\hline Local recurrence & $10(5.6 \%)$ & $3(7.5 \%)$ & & 0.71 \\
\hline Bladder recurrence & $102(57.0 \%)$ & $22(55.0 \%)$ & 0.052 & 0.819 \\
\hline $\begin{array}{l}\text { Contralateral } \\
\text { recurrence }\end{array}$ & $13(7.3 \%)$ & $1(2.5 \%)$ & & 0.474 \\
\hline Metastasis & $6(3.4 \%)$ & $4(10.0 \%)$ & & 0.087 \\
\hline
\end{tabular}

eGFR: estimated glomerular filtration rate; LVI: lymphovascular invasion. 


\begin{tabular}{|c|c|c|c|c|c|c|c|c|}
\hline \multirow[t]{3}{*}{ Variables } & \multicolumn{4}{|c|}{ CSS } & \multicolumn{4}{|c|}{ OS } \\
\hline & \multicolumn{2}{|c|}{ Univariable analysis } & \multicolumn{2}{|c|}{ Multivariable analysis } & \multicolumn{2}{|c|}{ Univariable analysis } & \multicolumn{2}{|c|}{ Multivariable analysis } \\
\hline & HR (95\% CI) & $\mathbf{p}$ & HR (95\% CI) & $\mathbf{p}$ & HR (95\% CI) & $\mathbf{p}$ & HR (95\% CI) & $\mathbf{p}$ \\
\hline Sex & $\begin{array}{c}1.437 \\
(0.941-2.193)\end{array}$ & 0.093 & $\begin{array}{c}1.088 \\
(0.688-1.721)\end{array}$ & 0.717 & $1.451(0.97-2.17)$ & 0.07 & $1.167(0.758-1.799)$ & 0.483 \\
\hline Age & $\begin{array}{c}1.037 \\
(1.011-1.065) \\
\end{array}$ & $0.005^{*}$ & $\begin{array}{c}1.03 \\
(1.003-1.057) \\
\end{array}$ & $0.028^{*}$ & $1.037(1.012-1.063)$ & $0.004^{*}$ & 1.03 (1.005-1.056) & $0.019^{*}$ \\
\hline BMI & $\begin{array}{c}0.972 \\
(0.917-1.031) \\
\end{array}$ & 0.35 & $\begin{array}{c}0.982 \\
(0.922-1.047) \\
\end{array}$ & 0.585 & $0.969(0.916-1.023)$ & 0.275 & $978(0.921-1.038)$ & 0.457 \\
\hline Side, left vs. right & $\begin{array}{c}0.958 \\
(0.635-1.445) \\
\end{array}$ & 0.837 & $\begin{array}{c}0.998 \\
(0.656-1517) \\
\end{array}$ & 0.991 & $0.935(0.632-1.383)$ & 0.737 & $0.986(0.661-1.471)$ & 0.945 \\
\hline $\begin{array}{l}\text { History of UTUC, yes } \\
\text { vs. no }\end{array}$ & $\begin{array}{c}11.377 \\
(6.119-21.150) \\
\end{array}$ & $<0.001^{*}$ & $\begin{array}{c}9.416 \\
(4.689-18.907) \\
\end{array}$ & $\begin{array}{c}<0.00 \\
1^{*}\end{array}$ & $\begin{array}{c}10.463 \\
(5.677-19.284) \\
\end{array}$ & $<0.001^{*}$ & $\begin{array}{c}9.022(4.577- \\
17.784)\end{array}$ & $\underset{*}{<0.001}$ \\
\hline $\begin{array}{l}\text { History of bladder } \\
\text { carcinoma, yes vs. no }\end{array}$ & $\begin{array}{c}1.148 \\
(0.616-2.138) \\
\end{array}$ & 0.664 & $\begin{array}{c}1.403 \\
(0.728-2.703) \\
\end{array}$ & 0.312 & $1.029(0.554-1.912)$ & 0.927 & $1.228(0.642-2.35)$ & 0.535 \\
\hline $\begin{array}{l}\text { Surgery type, } \\
\text { reference SU }\end{array}$ & $\begin{array}{c}0.722 \\
(0.4-1.303) \\
\end{array}$ & 0.279 & $\begin{array}{c}0.862 \\
(0.469-1.585)\end{array}$ & 0.633 & $0.644(0.359-1.156)$ & 0.14 & $0.764(0.419-1.392)$ & 0.379 \\
\hline $\begin{array}{l}\text { Surgery approach, } \\
\text { reference laproscopy }\end{array}$ & $\begin{array}{c}0.917 \\
(0.581-1.449)\end{array}$ & 0.711 & $\begin{array}{c}1.048 \\
(0.646-1.689)\end{array}$ & 0.85 & $1.02(0.665-1.563)$ & 0.928 & $1.165(0.742-1.831)$ & 0.506 \\
\hline T stage & $\begin{array}{c}1.607 \\
(1.214-2.127) \\
\end{array}$ & $0.001^{*}$ & $\begin{array}{c}1.474 \\
(1.027-2.115) \\
\end{array}$ & $0.035^{*}$ & 1.53 (1.174-1.995) & $0.002^{*}$ & $1.341(0.974-1.847)$ & 0.072 \\
\hline
\end{tabular}




\section{Title}

\begin{tabular}{|l|c|c|c|c|c|c|c|c|}
\hline Grade & $\begin{array}{c}1.882 \\
(1.264-2.803)\end{array}$ & 0.2 & $\begin{array}{c}1.098 \\
(0.662-1.824)\end{array}$ & 0.717 & $1.865(1.277-2.724)$ & $0.001^{*}$ & $1.132(0.7-1.832)$ & 0.613 \\
\hline LVI & $\begin{array}{c}1.039 \\
(0.453-2.386)\end{array}$ & 0.927 & $\begin{array}{c}0.772 \\
(0.307-1.945)\end{array}$ & 0.584 & $1.099(0.508-2.376)$ & 0.81 & $0.806(0.339-1.919)$ & 0.626 \\
\hline Tumour length & $\begin{array}{c}1.126 \\
(1.055-1.201)\end{array}$ & $<0.001^{*}$ & $\begin{array}{c}1.089 \\
(1.014-1.169)\end{array}$ & $\mathbf{0 . 0 1 8 ^ { * }}$ & $1.127(1.06-1.199)$ & $<0.001^{*}$ & $1.083(1.013-1.159)$ & $\mathbf{0 . 0 1 9}$ \\
\hline Necrosis & $\begin{array}{c}1.184 \\
(0.678-2.066)\end{array}$ & 0.552 & $\begin{array}{c}0.947 \\
(0.51-1.759)\end{array}$ & 0.863 & $1.309(0.784-2.186)$ & 0.304 & $1.104(0.62-1.968)$ & 0.626 \\
\hline
\end{tabular}

CI: confidence interval; HR: hazard ratio; LVI: lymphovascular invasion. 


\begin{tabular}{|c|c|c|c|c|c|c|c|c|c|c|c|c|}
\hline \multirow[t]{3}{*}{ Variables } & \multicolumn{3}{|c|}{ Local recurrence-free survival } & \multicolumn{3}{|c|}{$\begin{array}{c}\text { Intravesicular recurrence-free } \\
\text { survival }\end{array}$} & \multicolumn{3}{|c|}{$\begin{array}{c}\text { Contralateral recurrence-free } \\
\text { survival }\end{array}$} & \multicolumn{3}{|c|}{ Distant metastasis-free survival } \\
\hline & \multirow{2}{*}{$\begin{array}{c}\text { Univariable } \\
\mathbf{p}\end{array}$} & \multicolumn{2}{|c|}{ Multivariable } & \multirow{2}{*}{$\begin{array}{c}\text { Univariable } \\
\mathbf{p}\end{array}$} & \multicolumn{2}{|c|}{ Multivariable } & \multirow{2}{*}{$\frac{\text { Univariable }}{p}$} & \multicolumn{2}{|c|}{ Multivariable } & \multirow{2}{*}{$\begin{array}{c}\text { Univariable } \\
\mathbf{p}\end{array}$} & \multicolumn{2}{|c|}{ Multivariable } \\
\hline & & $\begin{array}{c}\text { HR } \\
(95 \% \mathrm{CI})\end{array}$ & $\mathbf{p}$ & & $\begin{array}{c}\text { HR } \\
(95 \% \mathrm{CI})\end{array}$ & $\mathbf{p}$ & & $\begin{array}{c}\text { HR } \\
(95 \% \mathrm{CI})\end{array}$ & $\mathbf{p}$ & & $\begin{array}{c}\text { HR } \\
(95 \% \mathrm{CI})\end{array}$ & $\mathbf{P}$ \\
\hline Sex & 0.109 & & 0.068 & 0.197 & & 0.158 & 0.505 & & 0.122 & 0.14 & & 0.177 \\
\hline Age & 0.351 & & 0.066 & $0.028^{*}$ & & 0.157 & 0.089 & $\begin{array}{c}0.903 \\
(0.848- \\
0.962)\end{array}$ & $0.002^{*}$ & 0.139 & $\begin{array}{c}1.126 \\
(1.012- \\
1.254)\end{array}$ & $0.03^{*}$ \\
\hline BMI & 0.505 & & 0.212 & 0.414 & & 0.704 & 0.313 & $\begin{array}{c}0.816 \\
(0.675- \\
0.985)\end{array}$ & $0.034^{*}$ & 0.975 & & 0.488 \\
\hline $\begin{array}{l}\text { Side, left vs. } \\
\text { right }\end{array}$ & 0.604 & & 0.693 & 0.379 & & 0.148 & 0.687 & & 0.824 & 0.828 & & 0.667 \\
\hline $\begin{array}{l}\text { History of } \\
\text { UTUC, yes } \\
\text { vs. no }\end{array}$ & 0.745 & & 0.988 & 0.415 & & 0.572 & 0.158 & & 0.172 & 0.738 & & 0.991 \\
\hline $\begin{array}{l}\text { History of } \\
\text { bladder } \\
\text { carcinoma, } \\
\text { yes vs. no }\end{array}$ & 0.511 & & 0.98 & $<0.001^{*}$ & $\begin{array}{c}2.129 \\
\left(1.385^{-}\right. \\
3.273)\end{array}$ & $0.001^{*}$ & 0.823 & & 0.434 & 0.454 & & 0.204 \\
\hline
\end{tabular}




\begin{tabular}{|c|c|c|c|c|c|c|c|c|c|c|c|c|}
\hline $\begin{array}{l}\text { Surgery type, } \\
\text { reference SU }\end{array}$ & $0.033^{*}$ & $\begin{array}{c}5.069 \\
(1.029- \\
24.968)\end{array}$ & $0.046^{*}$ & 0.665 & & 0.94 & 0.214 & & 0.129 & 0.093 & $\begin{array}{c}6.497 \\
(1.196- \\
35.283)\end{array}$ & $0.03^{*}$ \\
\hline $\begin{array}{l}\text { Surgery } \\
\text { approach, } \\
\text { reference } \\
\text { laparoscopy }\end{array}$ & 0.211 & & 0.149 & 0.164 & & 0.256 & 0.768 & & 0.292 & 0.801 & & 0.796 \\
\hline T stage & 0.801 & & 0.947 & 0.41 & & 0.107 & 0.164 & 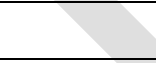 & 0.055 & $0.018^{*}$ & & 0.139 \\
\hline Grade & 0.862 & & 0.448 & 0.667 & 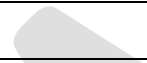 & 0.127 & 0.167 & 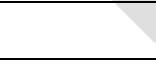 & 0.88 & 0.096 & & 0.922 \\
\hline LVI & 0.063 & & 0.692 & 0.704 & & 0.682 & 0.5 & & 0.983 & $<0.001^{*}$ & $\begin{array}{c}8.943 \\
(1.518- \\
52.685)\end{array}$ & $0.015^{*}$ \\
\hline $\begin{array}{l}\text { Tumour } \\
\text { length }\end{array}$ & 0.363 & & 0.515 & $0.043^{*}$ & & 0.061 & $0.013^{*}$ & $\begin{array}{c}1.287 \\
(1.045- \\
1.584)\end{array}$ & $0.017^{*}$ & 0.461 & & 0.313 \\
\hline Necrosis & 0.455 & & 0.933 & 0.13 & $\begin{array}{c}2.12 \\
(1.212- \\
3.708)\end{array}$ & $0.008^{*}$ & 0.198 & & 0.212 & 0.616 & & 0.336 \\
\hline
\end{tabular}

BMI: body mass index; CI: confidence interval; HR: hazard ratio; LVI: lymphovascular invasion. 